\title{
Compósitos à base de gesso com resíduos de EVA e vermiculita
}

\author{
Marilia P. de Oliveira ${ }^{1}$, Normando P. Barbosa ${ }^{2}$, Sandro M. Torres ${ }^{3}$, \\ Antonio F. Leal ${ }^{3}$ \& Cibelle G. Silva ${ }^{4}$
}

\begin{abstract}
RESUMO
O gesso é um dos materiais de construção mais antigos de que se tem conhecimento. Algumas de suas propriedades lhes conferem vantagens, tais como resistência ao fogo e isolamentos térmico e acústico. Objetivou-se, com este trabalho, avaliar as propriedades físico-mecânicas de compósitos à base de gesso com a incorporação de resíduos da indústria de calçados, o etileno acetato de vinila (EVA) e a vermiculita. O desenvolvimento desses compósitos tem como propósito a produção de elementos de revestimento para proteção térmica de alvenarias. Para determinar a influência dos teores de resíduo de EVA e vermiculita e da relação água/gesso nas propriedades massa específica aparente e nas resistências a flexão e a compressão, foram incorporados cinco diferentes percentuais desses materiais, combinados com três relações água/gesso. Os resultados foram analisados por meio da estatística multivariável e indicaram que a massa específica aparente de ambos os compósitos e a resistência à flexão do compósito com vermiculita, mostraram maior dependência da relação água/gesso; por sua vez, o percentual de agregado apresentou maior influência na resistência à flexão do compósito com EVA e na resistência a compressão de ambos os compósitos.
\end{abstract}

Palavras-chave: resistência à flexão, resistência à compressão, massa específica

\section{Gypsum-based composites with EVA waste and vermiculite}

\begin{abstract}
Gypsum is one of the oldest known building materials. Some of its properties confer advantages such as fire resistance, thermal and acoustic insulation. This work aims to study the physical and mechanical properties of gypsum-based composite with the incorporation of residues from the footwear industry ethylene vinyl acetate (EVA) and vermiculite. The aim to develop these composites is to produce components for thermal protection of masonry. To determine the influence of different residue levels of EVA and vermiculite, and the water/plaster ratio on the bulk density, flexural and compressive strength, five different percentages of these materials were incorporated combined with three water/plaster ratios. The results were analyzed by multivariate statistics and indicated that the density of both composites and the flexural strength of the composite with vermiculite had a greater influence of the water/plaster ratio, while the percentage of aggregate shows greater influence on the flexural strength of the composite with EVA and compressive strength of both composites.
\end{abstract}

Key words: flexural strength, compressive strength, bulk density

DCAT/UFERSA, Av. Francisco Mota, 572, Bairro Costa e Silva, CEP 59625-900, Mossoró, RN. Fone: (84) 3317-8323. E-mail: mariliapolive@yahoo.com.br

DECA/UFPB, Campus Universitário, s/n, CEP 58050-900, João Pessoa-PB. Fone: (83) 3216-7310. E-mail: nperazzob@yahoo.com.br

DEMAT/UFPB. Fone: (83) 3216-7310. E-mail: sandromardentorres@yahoo.co.uk; antoniofleal@gmail.com

${ }^{4}$ UFCG, Rua Maria Aparecida Carneiro 330, Ap. 302-A, Catolé, CEP 58410-367, Campina Grande, PB. Fone: (83) 8815-1116. E-mail: cibelleguimaraes@yahoo.com.br 


\section{INTRODUÇÃO}

O gesso é um dos materiais de construção mais antigos de que se tem notícia por apresentar vantagens, como boas propriedades termo-acústicas, além de possuir boa resistência ao fogo.

Uma das maiores deficiências do gesso como material de construção é sua suscetibilidade à água ainda que, atualmente, este aspecto esteja sendo melhorado mediante a incorporação de aditivos à base de silicones ou polímeros. Segundo Colak (2001), polímeros solúveis em água melhoraram o comportamento elástico em matrizes de gesso.

Pesquisas relacionadas à utilização de gesso, como matriz para a produção de compósitos, têm sido desenvolvidas incorporando-se materiais, tais como fibras de vidro, fibras de sisal, polpa de celulose e partículas de madeira, cortiça, vermiculita e até resíduos industriais.

Em seu estado natural a vermiculita tem pouca aplicação prática. No entanto, depois de esfoliada ela se torna material de baixa densidade com excelentes propriedades termo-isolante e cada floco esfoliado aprisiona ar em seu interior (Lorenzon et al., 2004).

Verbeek \& Du Plessis (2005) determinaram a influência do percentual de vermiculita na densidade e na resistência à flexão de um compósito gesso-vermiculita e obtiveram, com o teor de $25 \%$ de vermiculita para o compósito, a densidade de aproximadamente $450 \mathrm{~kg} \mathrm{~m}^{-3} \mathrm{e} 0,4 \mathrm{MPa}$ de resistência à flexão enquanto com $50 \%$ de vermiculita a massa específica aparente aumentou para cerca de $800 \mathrm{~kg} \mathrm{~m}^{-3}$ e a resistência à flexão para $1,6 \mathrm{MPa}$.

Compósito à base de gesso com fibras do caule do algodão foi estudado por Li et al. (2003) os quais relataram que as fibras de algodão foram tratadas com emulsão de estireno acrílico para melhorar não apenas a aderência com a matriz de gesso com adições de cal, cimento Portland e escória mas também, consequentemente, o desempenho mecânico. Verificou-se que o módulo de elasticidade diminuiu em relação ao compósito com fibras não tratadas, uma vez que, uma camada flexível foi formada entre as fibras tratadas com emulsão acrílica.

Haselein et al. (2002) confeccionaram chapas aglomeradas utilizando gesso como material cimentante e papel reciclado dissociado, como reforço. A inclusão das fibras de papel provocou aumento de $64,7 \%$ na resistência à flexão, $77,2 \%$ na dureza Janka e 49,6\% na resistência ao arrancamento de parafusos, em relação à chapa de gesso puro.

Estudos relacionados à influência do teor de partículas de madeira na densidade e nas propriedades térmicas de compósitos à base de gesso foram feitos por Bekhta \& Dobrowolska (2005), que obtiveram placas prensadas com teores de partículas de 0 a $35 \%$ cuja densidade variou de 850 a $1350 \mathrm{~kg} \mathrm{~m}^{-3} \mathrm{e}$ a condutividade térmica se situou entre $0,189 \mathrm{e}$ $0,753 \mathrm{~W} \mathrm{~m}^{-1} \mathrm{~K}^{-1}$.

Hernández-Olivares et al. (1999) estudaram as propriedades mecânicas e térmicas de um compósito gesso-cortiça em diferentes percentuais de cortiça. Com uma relação água-gesso de 0,8 a resistência a flexão foi de $2,26 \mathrm{MPa}$ e a resistência a compressão foi 2,27 MPa. Com a relação água-gesso igual a
0,6, a resistência a flexão e a compressão foram de 2,28 e 2,34 $\mathrm{MPa}$, respectivamente.

O EVA (Ethylene Vinyl Acetate) é um copolímero formado pelo encadeamento de sequências aleatórias de unidades repetitivas da polimerização do eteno e acetato de vinila. As espumas obtidas com esta resina são encontradas no mercado com densidades variando de 90 a $350 \mathrm{~kg} \mathrm{~m}^{-3}$ (Azevedo et al., 2009).

O EVA aplicado principalmente na indústria de calçados gera resíduos no processo de fabricação das placas expandidas e na fabricação dos calçados, um excedente que se torna um problema na hora do destino final, haja vista tratar-se de material não biodegradável.

Os solados produzidos com EVA expandido possuem densidades menores comparados ao PVC expandido e apresentam células fechadas, o que diminui a absorção de água (Zettera et al., 2005).

Alguns usos desse material na construção civil em matrizes à base de cimento Portland foram reportados na literatura.

Melo \& Lima Filho (2009) estudaram a aplicação do EVA como agregado leve em substituição ao agregado natural em compósitos cimentícios para a produção de blocos leves.

Santiago et al. (2009) afirmam ser possível a utilização de resíduos sólidos da indústria de calçados na construção civil como agregado para a produção de concreto leve e que, apesar da redução na resistência a compressão e no módulo de elasticidade, tal agregado permite a produção de concreto estrutural de peso leve.

Cavalcanti Filho et al. (2010) produziram caixas de compósito cimento-resíduo de EVA na construção de colméias Langstroth para substituir as caixas de madeira e observaram que as caixas feitas do compósito proporcionavam, às abelhas, condições favoráveis de reprodução.

Com este trabalho objetivou-se avaliar as propriedades físico-mecânicas de compósitos à base de gesso com a adição de vermiculita e de resíduo da indústria de calçados, visando à produção de elementos de revestimento para proteção térmica de alvenarias.

\section{Material e MÉTOdos}

Os materiais utilizados na moldagem dos compósitos foram os seguintes:

Gesso - Foi utilizado gesso natural proveniente do polo gesseiro do Araripe, no Estado de Pernambuco, com as características química, física e mecânicas apresentadas na Tabela 1.

Vermiculita - Utilizou-se vermiculita expandida produzida industrialmente, de massa unitária de $0,19 \mathrm{~g} \mathrm{~cm}^{-3} \mathrm{e}$ caracterização granulométrica apresentada na Figura 1.

EVA (Etileno Acetato de Vinila) - O resíduo de EVA foi coletado em uma indústria de calçados na cidade de João Pessoa, PB, apresentando massa unitária de $0,22 \mathrm{~g} \mathrm{~cm}^{-3} \mathrm{e}$ composição granulométrica apresentada na Figura 2.

Água - A água utilizada foi fornecida pelo sistema de abastecimento da cidade de João Pessoa, PB 
Tabela 1. Características químicas, físicas e mecânicas do gesso

\begin{tabular}{lrc}
\hline \multicolumn{1}{c}{ Características } & Valores & $\begin{array}{r}\text { Limite }- \text { NBR 13207 } \\
\text { (ABNT, 1994) }\end{array}$ \\
Químicas & & \\
Óxido de cálcio $(\mathrm{CaO})(\%)$ & 43,26 & $>38$ \\
Anidrido sulfúrico $\left(\mathrm{SO}_{3}\right)(\%)$ & 54,96 & $>53$ \\
Óxido de magnésio $(\mathrm{MgO})(\%)$ & 0,09 & \\
Físicas e mecânicas & & \\
Módulo de finura & 0,08 & $<1,10$ \\
Massa unitária $\left(\mathrm{g} \mathrm{cm}^{-3}\right)$ & 0,62 & $<0,70$ \\
Massa específica real $\left(\mathrm{g} \mathrm{cm}^{-3}\right)$ & 2,60 & \\
Área específica $\left(\mathrm{cm}^{2} \mathrm{~g}^{-1}\right)$ & 7643,00 & \\
Consistência normal $\left(\mathrm{a} \mathrm{g}^{-1}\right)$ & 0,60 & $>10$ \\
Tempo de início de pega (min) & 18,95 & $>45$ \\
Tempo de fim de pega (min) & 34,30 & $>8,4$ \\
Resistência à compressão (MPa) & 9,00 & $>3,0$ \\
Resistência à tração na flexão (MPa) & 3,90 & \\
\hline
\end{tabular}

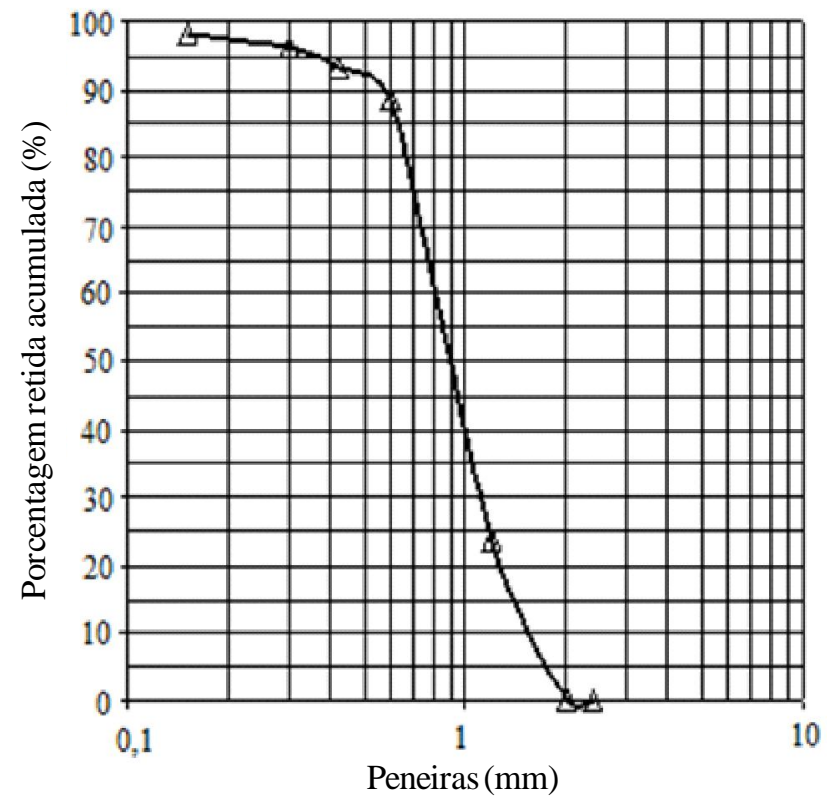

Figura 1. Curva granulométrica da vermiculita

Para determinar a influência dos teores de adição e da relação água/gesso no comportamento físico-mecânico dos compósitos, foram estudados os efeitos das variáveis: teor de adição de vermiculita e de EVA e relação água/gesso.

Nesta etapa foi utilizado um planejamento fatorial. O arranjo experimental adotado incluiu dois fatores: percentual de adição, com seis níveis $(0,5,10,15,20$ e $25 \%)$, em massa e relação água/gesso com três níveis, sendo $(0,8,0,9$ e 1,0$)$ para o compósito com vermiculita e $(0,7,0,8$ e 0,9$)$ para o compósito com EVA. Os ensaios foram realizados em três repetições aleatórias.

Os critérios para escolha dos teores limites de adição e relação água/gesso foram de acordo com a trabalhabilidade de cada compósito. Taxas de adição acima de $25 \%$ dificultavam a mistura, que foi realizada manualmente.

Três séries de três corpos de prova foram produzidas para cada mistura, com dimensões 40 x 40 x $160 \mathrm{~mm}$. Cerca de $1 \mathrm{~h}$ após a moldagem os corpos de prova foram retirados dos moldes, tempo suficiente para que adquirissem resistência a

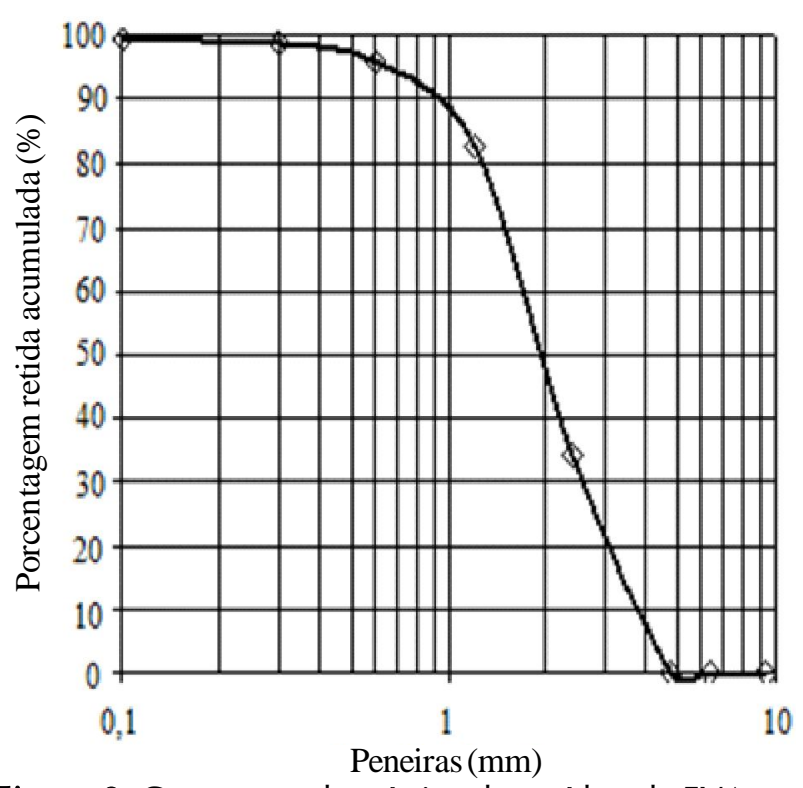

Figura 2. Curva granulométrica do resíduo de EVA

fim de serem manuseados e acondicionados em temperatura ambiente durante $24 \mathrm{~h}$ e posteriormente colocados em estufa a $40 \pm 5^{\circ} \mathrm{C}$ para acelerar o processo de secagem, até se obter massa constante. A massa específica aparente foi determinada pela razão entre a massa do corpo de prova seco e seu volume. Os corpos de prova, já secos, foram pesados em uma balança eletrônica de precisão $0,01 \mathrm{~g}$ e, para se obter o volume, foi tomada a média de suas arestas utilizando-se um paquímetro.

A resistência à tração na flexão foi definida de acordo com o método da (ABNT, 2005a) - NBR 13279. Neste ensaio um carregamento central é aplicado ao corpo de prova prismático de 40 × 40 × $160 \mathrm{~mm}$, que é colocado sobre dois apoios afastados $100 \mathrm{~mm}$ entre si. A resistência à compressão axial foi determinada com as metades dos corpos de prova utilizados no ensaio de resistência a tração, conforme a mesma norma.

\section{RESULTADOS E DISCUSSÃO}

Para analisar a influência dos teores de adição da vermiculita e do EVA nas propriedades físico-mecânicas dos compósitos, levantou-se uma análise estatística multivariada utilizando-se o programa ORIGIN 7.0. Para a escolha da composição das placas tomou-se como base a resistência à tração na flexão de $2 \mathrm{MPa}$, de acordo com os requisitos para resistência à tração na flexão da ABNT (2005b) para argamassa de revestimento de paredes e tetos.

O modelo que representa a influência dos teores de adição da vermiculita e da relação água/gesso (a/g) na massa específica aparente do compósito é representado pela Eq. 1 e pelo gráfico de superfície de resposta na Figura 3A. Observase que o decréscimo da massa específica aparente é mais influenciado pelo aumento da relação a/g do que pela adição da vermiculita.

Para o compósito gesso-EVA a Eq. 2 representa o modelo escolhido para a massa específica aparente enquanto o gráfico da superfície de resposta é apresentado na Figura 3B. A relação 
A.

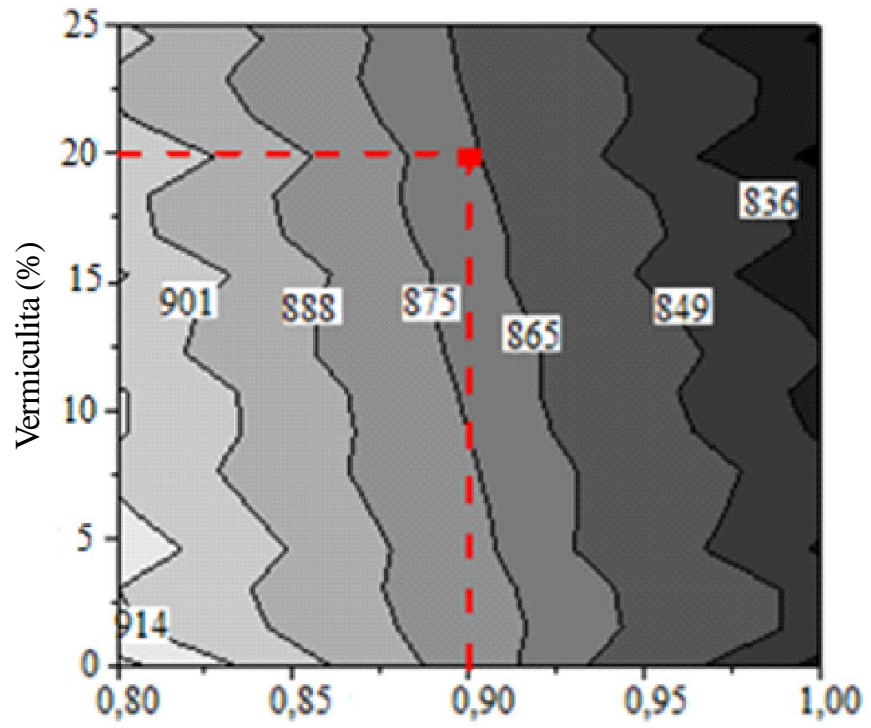

B.

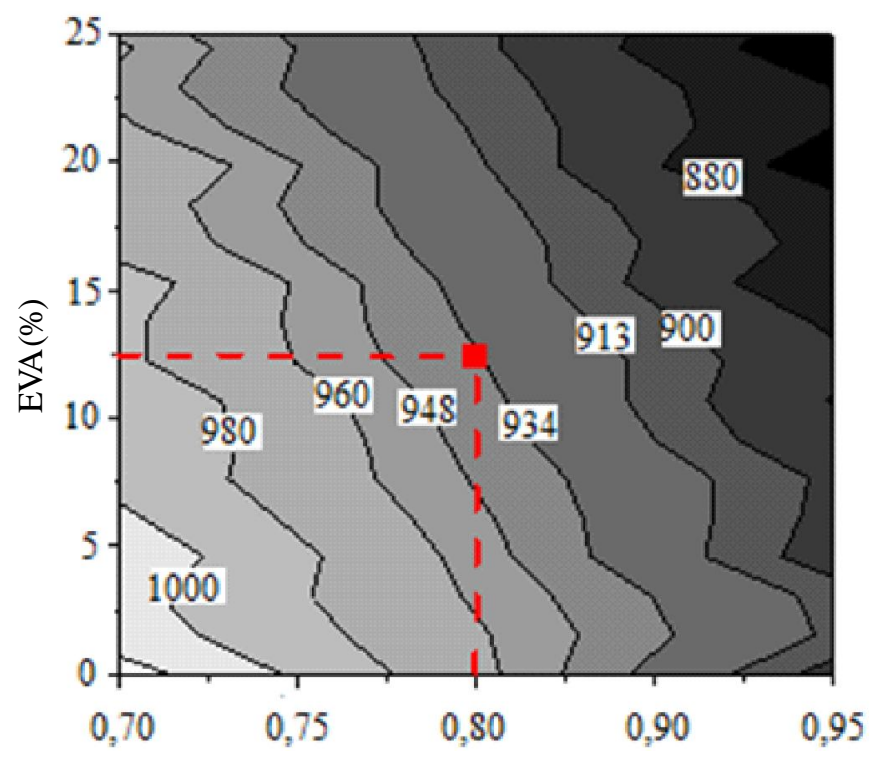

Relação água/gesso $(\mathrm{a} / \mathrm{g})$

Figura 3. Superfície de resposta da massa específica aparente $\left(\mathrm{kg} \mathrm{m}^{-3}\right)$ do compósito gesso-vermiculita (A) gesso-EVA (B)

a/g foi o parâmetro que mostrou maior contribuição no decréscimo da massa específica aparente.

$$
\begin{gathered}
\text { Massa Específica }\left(\mathrm{kg} \mathrm{m}^{-3}\right)=1326,62-494,17(\mathrm{a} / \mathrm{g}) \\
-75,68(\% \text { vermiculita })
\end{gathered}
$$

$$
\begin{gathered}
\text { Massa Específica }\left(\mathrm{kg} \mathrm{m}^{-3}\right)=1539,05-717,50(\mathrm{a} / \mathrm{g}) \\
-248,13(\% \mathrm{EVA})
\end{gathered}
$$

A resistência à tração na flexão (RTF) do compósito gessovermiculita é representada pela Eq. 3 e pelo gráfico da superfície de resposta na Figura 4; ambos os fatores contribuíram negativamente na resistência à flexão do compósito sendo a

\section{A.}

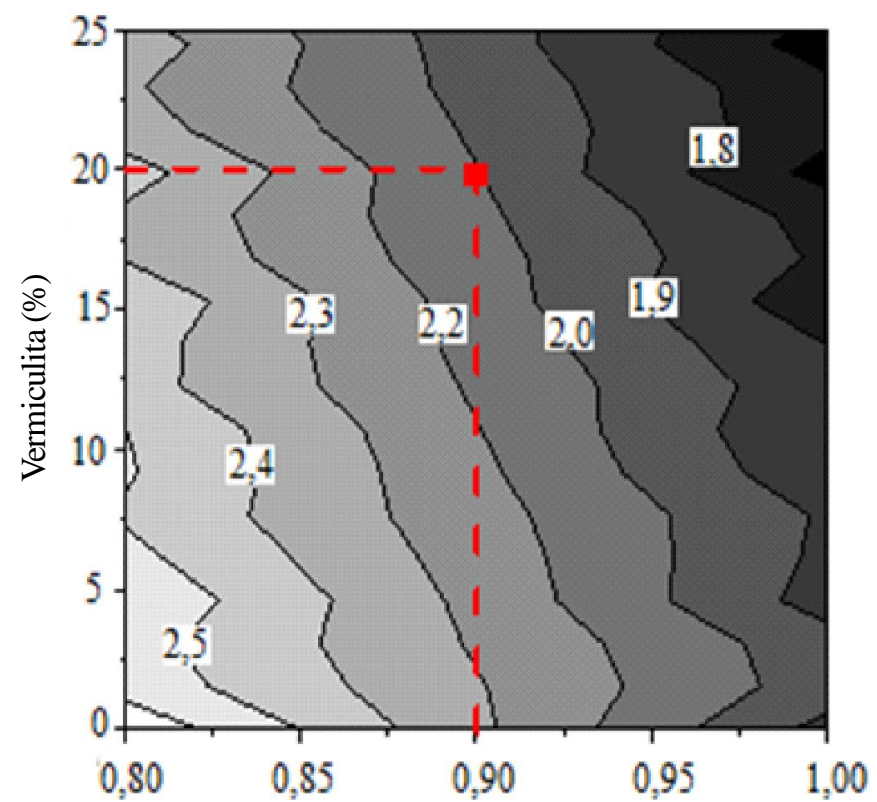

mesma mais afetada pela relação água/gesso. Com relação ao compósito gesso-EVA, a Eq. 4 e a Figura 4B demonstram que o decréscimo da resistência à flexão é maior devido à adição do EVA. Problemas de aderência entre o gesso e o EVA contribuíram para este decréscimo. Na Figura 7 observa-se que, de fato, os grãos de EVAnão interagem efetivamente com a matriz de gesso.

$$
\begin{gathered}
\operatorname{RTF}(\mathrm{MPa})=5,78-3,89(\mathrm{a} / \mathrm{g})-1,21(\% \text { vermiculita }) \\
\operatorname{RTF}(\mathrm{MPa})=6,16-4,33(\mathrm{a} / \mathrm{g})-5,88(\% \mathrm{EVA})
\end{gathered}
$$

A Eq. 5 e o gráfico da Figura 5 A representam a resistência à compressão (RC) do compósito gesso-vermiculita. De acordo

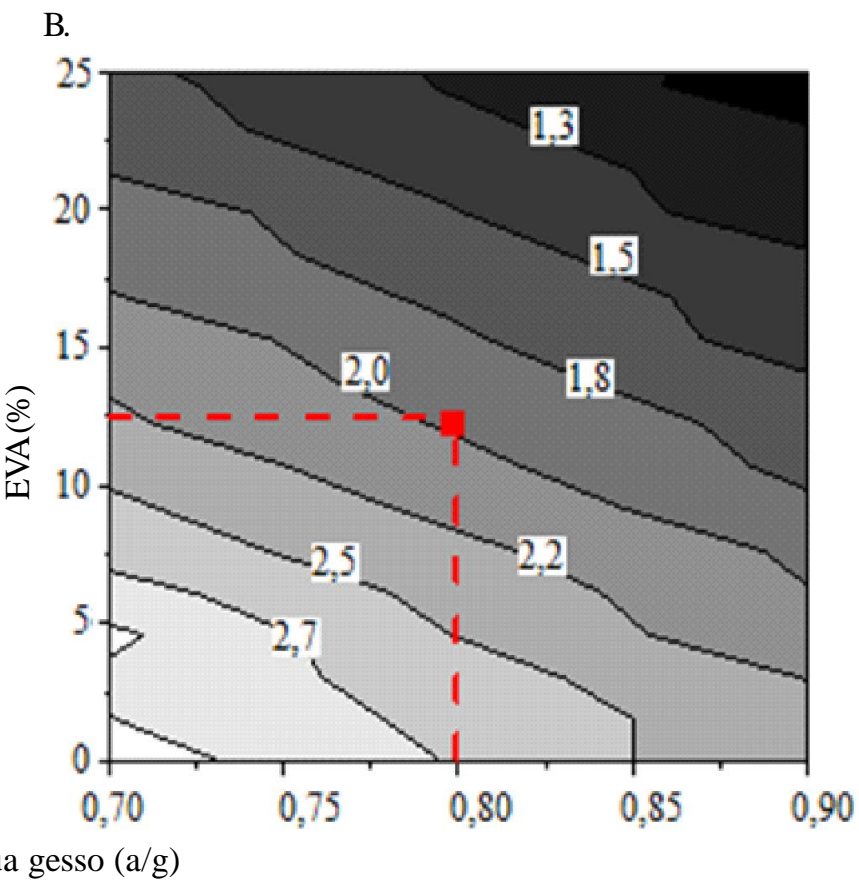

Figura 4. Superfície de resposta da resistência à tração na flexão (MPa) do compósito gesso-vermiculita (A) gesso-EVA (B) 
A.

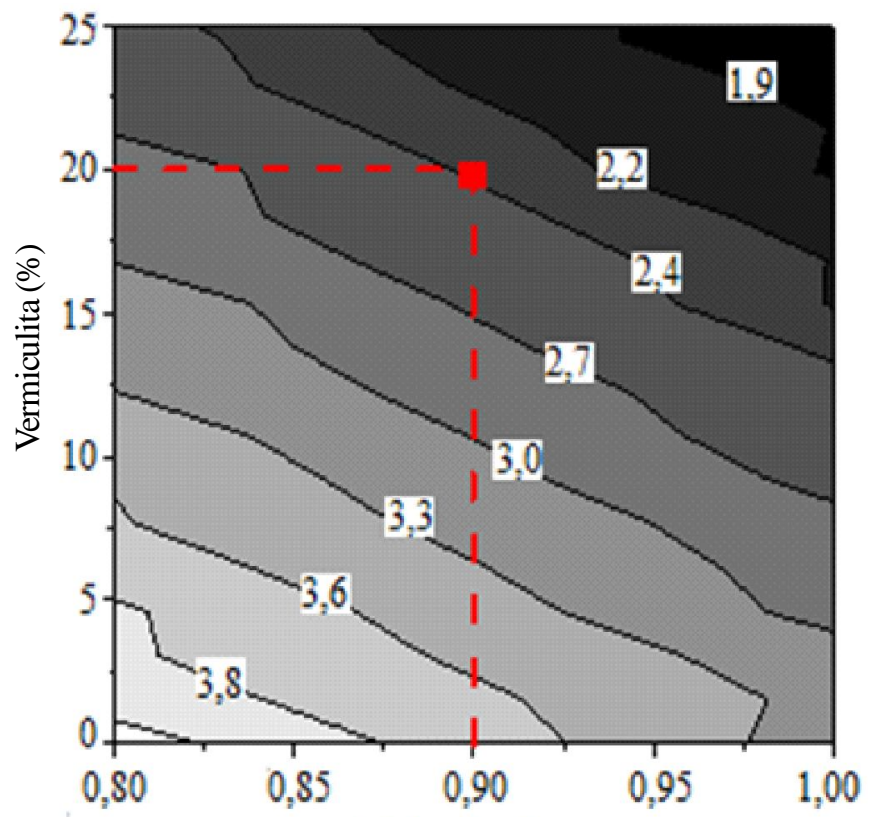

B.

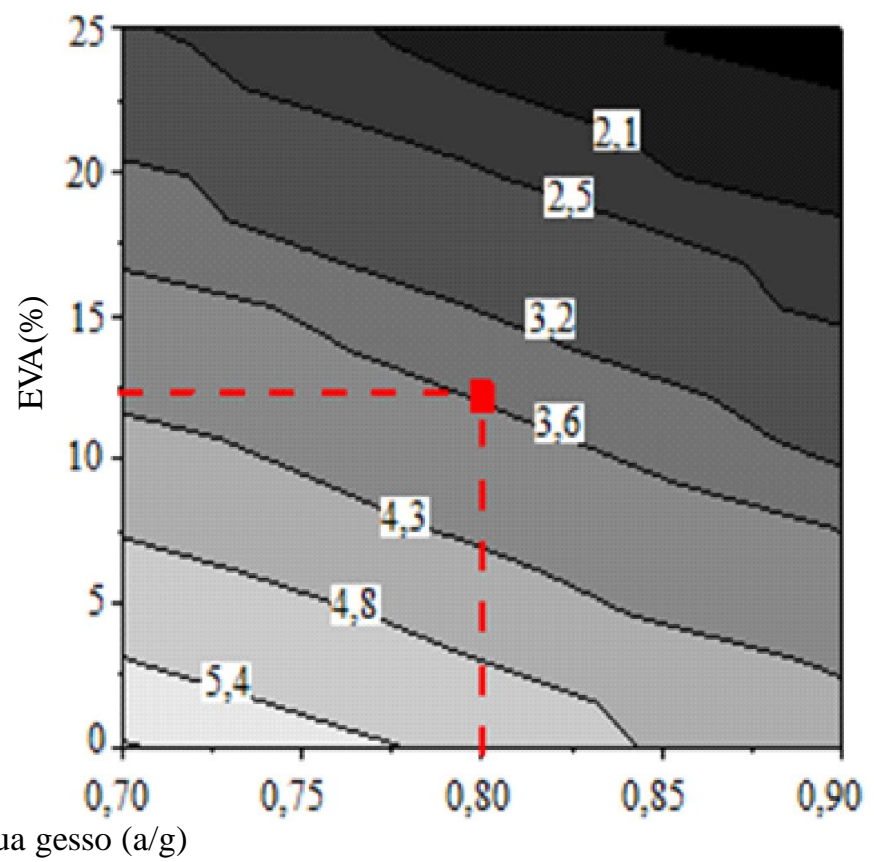

Figura 5. Superfície de resposta da resistência à compressão (MPa) do compósito gesso-vermiculita (A) gesso-EVA (B)

com esses resultados tem-se que a adição de vermiculita apresenta maior contribuição para diminuir a resistência do que a relação água/gesso. Os vazios da vermiculita podem ter sido parcialmente preenchidos pela matriz de gesso, como se observa na Figura 6. A resistência à compressão do compósito gesso-EVA é representada pela Eq. 6 e pela Figura 5B. O decréscimo da resistência à compressão também foi devido à adição de EVA.

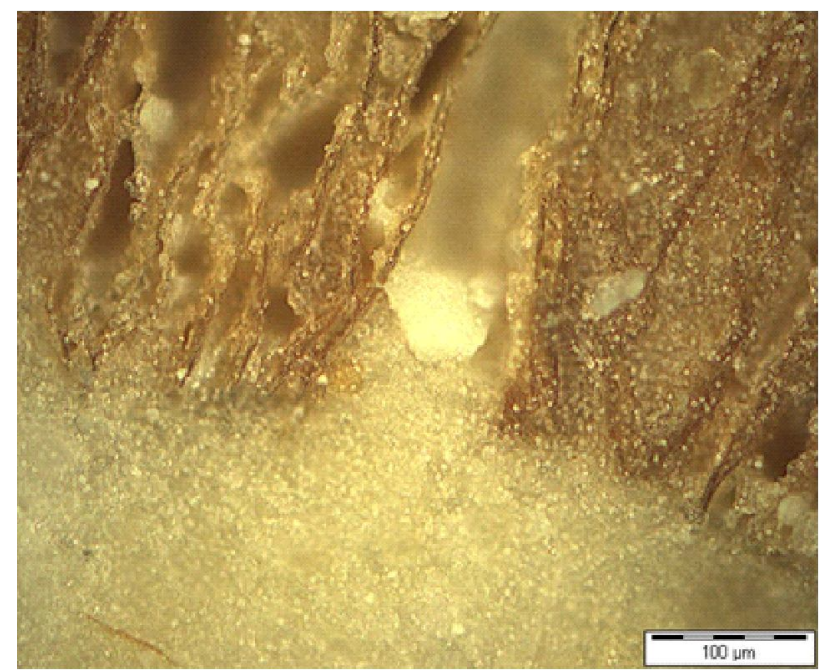

Figura 6. Detalhe da interface da matriz de gesso com a vermiculita [aumento 20x (100 $\mu \mathrm{m})$ ]

$$
\begin{gathered}
\mathrm{RC}(\mathrm{MPa})=8,68-5,53(\mathrm{a} / \mathrm{g})-6,63(\% \text { vermoculita }) \\
\mathrm{RC}(\mathrm{MPa})=12,23-8,75(\mathrm{a} / \mathrm{g})-13,47(\% \mathrm{EVA})
\end{gathered}
$$

Para reduzir-se a massa específica aparente do compósito com vermiculita tem-se que aumentar, sobremaneira, a relação água/gesso. Este aumento produzirá uma matriz mais porosa e menos densa. Por outro lado, para um ganho na resistência à tração na flexão deve-se diminuir principalmente a relação água/ gesso e, para aumentar a resistência à compressão, diminuir os percentuais de adição de vermiculita.

No caso do compósito com EVA para diminuir a massa específica aparente pode-se aumentar tanto a relação água/ gesso quanto o percentual de adição de EVA. Para se obter ganho de resistência à tração na flexão dos compósitos tornase conveniente diminuir principalmente o percentual de adição de EVA. O aumento na resistência à compressão também é obtido com a redução no percentual de EVA, assim como com a redução da relação água/gesso.

Em razão da influência das variáveis serem complexas, pois $\mathrm{o}$ aumento de uma delas pode melhorar uma propriedade e sua redução pode ser melhor para outra se decidiu, tomando-se como base a resistência à flexão de $2 \mathrm{MPa}$, fixar o percentual de adição da vermiculita em $20 \%$ e do EVA em $12,5 \%$. A relação água/gesso foi definida em 0,9 para o compósito gessovermiculita e 0,8 , para o compósito gesso-EVA (Tabela 2).

Tabela 2. Propriedades dos compósitos usados nas placas

\begin{tabular}{lcccc}
\hline \multicolumn{1}{c}{ Compósitos } & $\begin{array}{c}\% \\
\text { Agregado }\end{array}$ & $\begin{array}{c}\text { MSA } \\
\left(\mathbf{( k g ~ m}^{-3}\right)\end{array}$ & $\begin{array}{c}\mathbf{R T F} \\
(\mathbf{M P a})\end{array}$ & $\begin{array}{c}\mathbf{R C} \\
(\mathbf{M P a})\end{array}$ \\
Vermiculita & 20,0 & 866,0 & 2,0 & 2,4 \\
EVA & 12,5 & 934,0 & 2,0 & 3,6 \\
\hline
\end{tabular}

MSA - massa específica aparente, RTF - resistência à tração na flexão, RC - resistência à compressão

A Tabela 3 apresenta as propriedades dos compósitos com a relação água/gesso de 0,8 e o percentual de adição de $15 \%$.

Para a mesma relação água/gesso e o mesmo percentual de adição, nota-se que: a massa específica do compósito gessovermiculita é menor que a do gesso-EVA porque há uma proporção maior de vazios na vermiculita. A resistência à flexão 
Tabela 3. Propriedades físico-mecânicas dos compósitos

\begin{tabular}{lcr}
\hline Propriedades & Vermiculita & \multicolumn{1}{c}{ EVA } \\
Massa específica $\left(\mathrm{kg} \mathrm{m}^{-3}\right)$ & 920,0 & 928,0 \\
Resistência à tração na flexão $(\mathrm{MPa})$ & 2,5 & 1,8 \\
Resistência à compressão $(\mathrm{MPa})$ & 3,3 & 3,2 \\
\hline
\end{tabular}

do compósito gesso-vermiculita foi superior àquela do compósito gesso-EVA. No detalhe da Figura 6 é possível observar uma boa aderência entre a matriz de gesso e a vermiculita na qual o gesso preenche parcialmente as lamelas da vermiculita.

Na Figura 7 vê-se que há incorporação de bolhas de ar entre a matriz de gesso e o EVA, fato que pode explicar o decréscimo na resistência à flexão. Já para a resistência à compressão a diferença entre os compósitos foi pouca; é provável que os vazios entre as lamelas da vermiculita e a inadequada aderência do EVA tenham contribuído para valores de resistências similares.

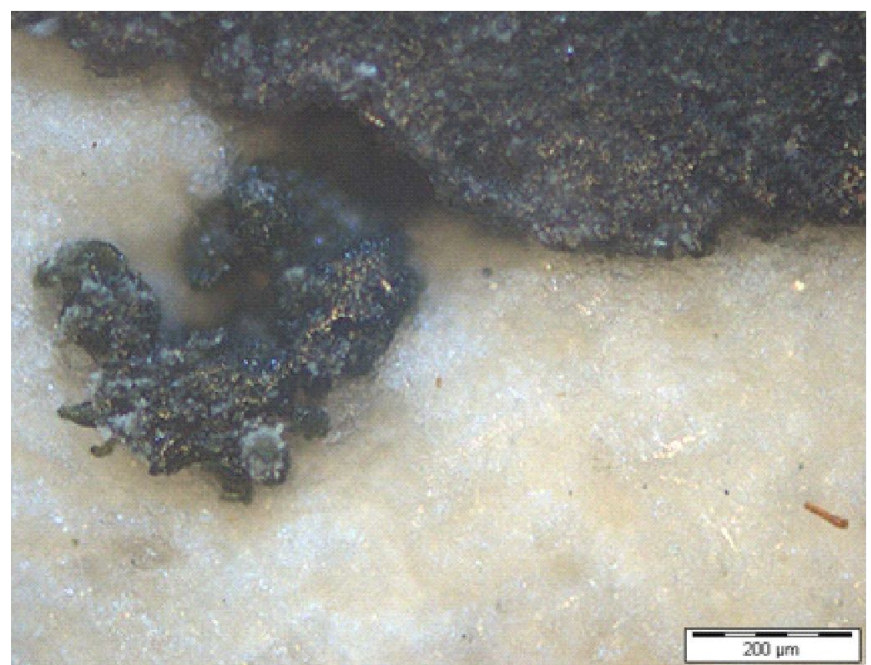

Figura 7. Detalhe da interface da matriz de gesso com o EVA [aumento 10x $(200 \mu \mathrm{m})$ ]

\section{ConclusõEs}

1. Os resíduos de etileno acetato de vinila (EVA) permitiram a geração de compósitos em matriz de gesso com boas propriedades mecânicas para fins de elaboração de placas visando à proteção térmica em alvenarias.

2. A relação água/gesso interfere mais na massa específica e na resistência à compressão dos compósitos do que o percentual de adição dos agregados nos níveis estudados.

3. A aderência das partículas de EVA na matriz de gesso não é tão boa como no caso da vermiculita. Esta deficiência de aderência é responsável pela menor resistência à flexão do compósito com EVA em relação àquele com vermiculita.

4. Os teores de vermiculita e de EVA que se mostraram mais adequados para a confecção dos elementos, foram de $20 \%$ de vermiculita e $12,5 \%$ de EVA.

\section{LITERATURA CITADA}

ABNT - Associação Brasileira de Normas Técnicas. NBR 13207. Gesso para construção civil: Especificação. Rio de Janeiro: ABNT, 1994. 2p.

ABNT - Associação Brasileira de Normas Técnicas. NBR 13279. Argamassa para assentamento e revestimento de paredes e tetos - Determinação da resistência à tração na flexão e à compressão. Rio de Janeiro: ABNT, 2005a. 9p.

ABNT - Associação Brasileira de Normas Técnicas. NBR 13281. Argamassa para assentamento e revestimento de paredes e tetos - requisitos. Rio de Janeiro: ABNT, 2005b. 7p.

Azevedo, J. B.; Chavéz, M. A.; Junior, R. A. C.; Oliveira, R. G. P.; Rabello, M. S. Propriedades físicas e mecânicas de espumas de EVA/EPDM. Revista Eletrônica de Materiais e Processos, v.4.1, p.38-44, 2009.

Bekhta, P.; Dobrowolska, E. Thermal properties of woodgypsum boards. Holz als Roh-und Werkstoff, p.427-428, 2005.

Cavalcanti Filho, O.; Soares, E. A.; Camerini, N. L.; Leal, A. F. Avaliação térmica do compósito cimento-resíduo de EVA (Etileno Acetato de Vinila) na construção de colméias Langstroth. Revista Eletrônica de Materiais e Processos, v.5, p.1-4, 2010.

Colak, A. Characteristics of acrylic latex-modified and partially epoxy-impregnated gypsum. Cement and Concrete Research, v.31, p.1539-1547, 2001.

Haselein, C. R.; Calegari, L.; Alberti, L. F.; Minello, A. L.; da Silva, P. A.; Pintos, R. G. F. Fabricação de chapas de partículas aglomeradas usando gesso como material cimentante. Ciência Florestal, v.12, p.81-88, 2002.

Hernández-Olivares, F.; Bollti, M. R.; Rio, M. del; Parga-Landa, B. Development of cork-gypsum composites for building applications. Construction and Building Materials, v.13, p.179-186, 1999.

Li, G.; Yu, Y.; Zhao, Z.; Li, J.; Li, C. Properties study of cotton stalk fiber/gypsum composite. Cement and Concrete Research, v.33, p.43-46, 2003.

Lorenzon, M. C. A.; Cidreira, R. G.; Rodrigues, E. H. V.; Dornelles, M. S.; Pereira Jr., G. Langstroth hive construction with cement-vermiculite. Scientia. Agricola, v.61, p.573-578, 2004.

Melo, A. B.; Lima Filho, M. R. F. Avaliação de desempenho estrutural de protótipo com paredes construídas com blocos de EVA. Revista Ambiente Construído, v.9, p.141-155, 2009.

Santiago, E. Q. R.; Lima, P. R. L.; Leite, M. B.; Toledo Filho, R. D. Mechanical behavior of recycled lightweight concrete using EVA waste and CDW under moderate. Revista IBRACON de Estruturas e Materiais, v.2, p.211-221, 2009.

Verbeek, C. J. R.; Du Plessis; B. J. G. W. Density and flexural strength of phosphogypsum-polymer composites. Construction and Building Materials, v.19, p.265-274, 2005.

Zettera, A. J.; Bianchi, O.; Zeni, N.; Ferreira, C. A. Caracterização de resíduos de copolímeros de etileno acetato de vinila EVA. Polímeros: Ciência e Tecnologia, v.15, p.73-78, 2005. 